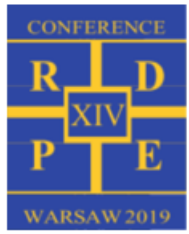

\title{
Improvements perspectives of cryogenics-based energy storage
}

\author{
Jimena Incer $^{1, *}$, Sarah Hamdy ${ }^{2}$, Tatiana Morosuk $^{3}$, and Georges Tsatsaronis ${ }^{4}$ \\ ${ }^{1}$ Energy Engineering Department, Campus El Gouna, Technische Universität Berlin, Marchstr.18, 10587 Berlin, \\ jimena.incervalverde@tu-berlin.de, Germany \\ ${ }^{2}$ Energy Engineering Department, Campus El Gouna, Technische Universität Berlin, Marchstr.18, 10587 Berlin, \\ sarah.hamdy@tu-berlin.de, Germany \\ ${ }^{3}$ Chair of Exergy-based methods for refrigeration systems, Technische Universität Berlin, Marchstr.18, 10587 Berlin, \\ tetyana.morozyuk@tu-berlin.de, Germany \\ ${ }^{4}$ Chair of Energy Engineering and Environmental Protection, Technische Universität Berlin, Marchstr.18, 10587 Berlin, \\ georgios.tsatsaronis@,tu-berlin.de, Germany
}

\begin{abstract}
A dvanced exergy-based analyses provide the information for potential of improvement of energyconversion systems from exergetic, economic and environmental point of view. These analyses are applied to Cryogenic-based Energy Storage (CES) also known as Liquid Air Energy Storage (LAES). Advantages such as (a) lack of geographical restrictions, (b) low environmental impact and the fact that it is (c) based on mature technology, drive further the research on this energy storage system. An adiabatic LAES system charged with Heylandt liquefaction of air process is analysed. Parameters such as exergy destruction, investment cost, cost associated with the exergy destruction, as well as the environmental impact associated with the thermodynamic irreversibilities are split into avoidable/unavoidable and endogenous/exogenous parts. Aspen Plus ${ }^{\circledR}$ software was used to simulate the LAES system and Engineering Equation Solver was used to conduct the conventional and advanced exergy-based analyses. The dependence of the improvement of each component with the rest of the system was found and all components present higher exogenous exergy destruction than endogenous. The component with the highest potential for improvement is the main heat exchanger in the discharge unit. Focusing on improvement of the components that were found to be the most inefficient ones with the highest exergy destruction, CES is expected to become thermodynamically and economically feasible.
\end{abstract}

\section{Introduction}

In the past years, especially since the Paris A greement at the 21st Conference of the Parties of the UNFCC, 195 countries have signed the agreement to keep the increase in global average temperature below $2{ }^{\circ} \mathrm{C}$ according to the pre-industrial levels and also to limit the increase to $\mathbf{1 . 5}$ ${ }^{\circ} \mathrm{C}$.

The rapid increase of renewables technologies such as wind and solar power integrated to the power grid is therefore promoted by many countries. Increasing interest in energy storage systems that do not endanger the power network stability while introducing fluctuating renewable energies to the grid are of great importance and are being rapidly developed. The share of renewable energy worldwide is supposed to reach $12.4 \%$ in 2023 in all sectors combined [1].

This paper discusses a feasible solution: Cryogenicbased Energy Storage, currently at precommercial state and still under development with a Technology Readiness Level of 8 (TRL=9 is the maximum) [5]. Contrary as the two most common and commercial large-scale energy storage technologies; Pumped Hydro Systems (PHS) and Compressed Air Energy Storage systems (CAES), CES does not present any geographical limitations and can be constructed much faster [2,3]. Efficiencies reported until now are promising for LAES, but the criteria where CES outstands the most is the considerably higher energy density than PHS and CAES.

The operation of the system consists in three units: charge, storage and discharge. The charging unit liquefies air when excess electricity is available, for this process different and well-proven air configuration systems can be used such as Kapitza, Linde, Heylandt Claude and variations of these configurations. The air is compressed to pressures around 150 bar and further expanded and liquefied [5]. The liquid air is stored at ambient pressure and low temperature of approximately $-196^{\circ} \mathrm{C}$ in storage vessels like those for liquid natural gas. Finally, the discharge unit can produce electricity when the demand is higher in a Rankine cycle, where the liquid air is regasified, superheated and expanded [4].

\section{State of the art}

In present, two LAES pilot plants exist in the United $\mathrm{K}$ ingdom, one research plant at the University of Birmingham of $350 \mathrm{~kW} / 2.5 \mathrm{M} \mathrm{Wh}$ and one of the private company Highview Power Storage of 2 M W. Currently, a 
bigger plant of $200 \mathrm{M} \mathrm{W}$ is being developed by the same company [4].

Even though, the CES concept was first introduced by the University of Newcastle more than forty years ago and it was first built more than twenty years ago by Mitsubishi Heavy Industries, it is still a relevant topic since considerably improvements were found that made the technology more attractive to investors and researchers. The first LAES pilot plant of 2.6 MW air liquefaction unit and power recovery system operated independently reported a low roundtrip efficiency and decreased the interest in this technology. Later, Hitachi researchers proposed a LAES plant that could reach $70 \%$ round trip efficiency if the integration of air liquefaction unit and power recovery regenerator is considered. Implementing solid materials and liquids as cold carriers in the heat recovery network are the key to reach this efficiency [4]. These results caught the attention of the private company, Highview Power Storage, that decided to work together with the University of Leeds in 2009 to demonstrate the advantages of this technology by building a $350 \mathrm{~kW} / 2.5$ MWh LAES system in Slough, Scotland. Two years later the plant became operational and is now in the research institute for CES in the University of Birmingham. The company completed the construction of a $5 \mathrm{MW} / 15 \mathrm{MWh}$ pre-commercial LAES system last year. The enterprise is also planning a $200 \mathrm{MW} / 1.2 \mathrm{GWh}$ GigaPlant that would prove the large-scale capacity of this system [6]. The costs are estimated to decrease at a learning rate of $17.5 \%$ [7]. The initial investment costs of a first-of-a-kind daily cycling unit are expected to reduce significantly from 880 - $2.580 € 2017 / \mathrm{kW}$ to $555-1.480 € 2017 / \mathrm{kW}$ when the technology reaches its maturity.

Recently, great potential in cost reduction and efficiency improvement through CES system integration was found [8].

This paper introduces advanced exergy-based methods split into avoidable/unavoidable and endogenous/exogenous to not only identify the limit to thermodynamic and cost improvements, but also to calculate the independency of the components with each other. The environmental impact of CES systems has also not yet been discussed in any of the reviewed literature. This paper aims to identify the economic potential of adiabatic CES systems through revealing the limit - the unavoidable part - of thermodynamic performance, interaction and dependence of results between each component - the endogenous part- and cost-effectiveness with advanced exergy-based methods.

\section{Methodology}

\subsection{Exergy-based analyses}

The exergy balance for the overall system can be written as [9]:

$$
\dot{E}_{F, t o t}=\dot{E}_{p, t o t}+\dot{E}_{D, t o t}+\dot{E}_{L, t o t}
$$

For the exergoeconomic analysis the cost associated with the exergy destruction is calculated according to [10]:

$$
\dot{C}_{D, k}=c_{F, k} \dot{E}_{D, k}
$$

With help of an economic analysis, the investment cost rate $\dot{Z}_{k}$ is calculated to proceed with the cost balances and the specific cost per unit of exergy of the streams exiting each component is calculated as [9]:

$$
\dot{C}_{P, k}=\dot{C}_{F, k}+\dot{Z}_{k}
$$

An exergoenvironmental analysis was also performed considering both exergy analysis and Life Cycle Assessment [11]. An environmental impact rate $\dot{B}_{j}$ and an environmental impact $b$ are assigned for each exergy stream. The Eco-indicator 99 is used as an environmental indicator assigning Eco-indicator points (Pts) when the categories ecosystem, human health and natural resources are compromised [13]. With this analysis, exergy destruction is related to the environmental impact for each component with the environmental impact per unit of exergy of fuel, $b_{F . k}$, as showed [10]:

$$
\dot{B}_{D, k}=b_{F, k} \dot{E}_{D, k}
$$

The environmental impact of electricity for low voltage electricity in Europe is $26 \mathrm{mPt} / \mathrm{kWh}$ or 7.22 $\mathrm{mPt} / \mathrm{MJ}$ [14]. Depending on the country where the energy storage system is located this impact may vary. The air entering the air compressors have an associated environmental impact of $0 \mathrm{mPt} / \mathrm{MJ}$.

\subsection{Advanced exergy-based analyses}

In the advanced exergy analysis the exergy destruction, cost associated with the exergy destruction, environmental impact and the investment cost are split into avoidable and unavoidable parts [12]. The unavoidable part is the part of the exergy destruction that is associated to technical limitations of a component. The exergy destruction can also be split into endogenous and exogenous. Operating at these conditions the system is referred to as the most efficient adiabatic LAES process. The avoidable part can be calculated as:

$$
\dot{E}_{D, k}{ }^{A V}=\dot{E}_{D, k}-\dot{E}_{D, k}{ }^{U N}
$$

Where at a specific designed point, $A$ :

$$
\dot{E}_{D, k, A}{ }^{U N}=\dot{E}_{P, k, A}\left(\frac{\dot{E}_{D, k}}{\dot{E}_{P, k}}\right)^{U N}
$$

Applying the same approach, the unavoidable investment cost and unavoidable cost rates can be calculated [16].

For the calculation of the endogenous and the exogenous parts of the exergy destruction, the theoretical 
fuel is calculated when the system operates at ideal conditions with no exergy destruction.

$$
\dot{E}_{F, t o t}^{T}=\dot{E}_{P, t o t}^{R=T \text { constant }}+0+\dot{E}_{L, t o t}^{T}
$$

To calculate the endogenous conditions, where all components behave at ideal conditions, except the component under study, hybrid conditions are calculated [12].

$$
\dot{E}_{F, t o t}^{H}=\dot{E}_{P, t o t}^{R=T=H}+\dot{E}_{D, k}^{H}+\dot{E}_{L, t o t}^{H}
$$

The part from the exergy destruction that is not endogenous is known as exogenous and combination of the avoidable and unavoidable part of the exergy destruction can be obtained through the term $\dot{E}_{D, k}^{U N, E N}[15]$.

$$
\dot{E}_{D, k}^{U N, E N}=\dot{E}_{P, k}^{E N} \times\left(\frac{E_{D, k}}{E_{P, k}}\right)^{U N}
$$

\section{Simulation}

The simulated process consists of a Heylandt process to liquefy the air in the charging process and a R ankine cycle for the discharge process. The detailed simulation results were reported in [8]. Figure 1 shows the flow diagram of the evaluated system. This configuration was simulated using Aspen Plus ${ }^{\circledR}$ software.

Table 1 shows the values for the design parameters of the components at a (a) real, (b) optimal and (c) worst adiabatic liquid air energy storage system simulation process.

Detailed simulation for the advanced analysis was performed on component level for the three conditions mentioned above.

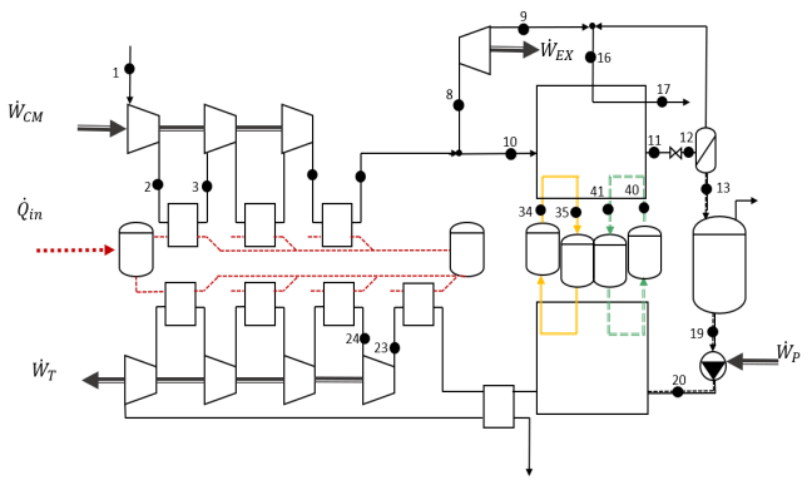

Fig. 1. Flow diagram of the adiabatic CES system

Table 1. Parameters for the real, unavoidable exergy destruction and unavoidable investment cost conditions

\begin{tabular}{|c|c|c|c|c|}
\hline Component & & Real & $\dot{E}_{D, k . A}{ }^{U N}$ & $\dot{Z}_{k \cdot \boldsymbol{A}}{ }^{U N}$ \\
\hline Compressors & $\eta(\%)$ & 85 & 90 & 70 \\
\hline
\end{tabular}

\begin{tabular}{|c|c|c|c|c|}
\hline Expander & $\eta(\%)$ & 84 & 88 & 60 \\
\hline Turbines & $\eta(\%)$ & 90 & 92 & 70 \\
\hline Pump & $\eta(\%)$ & 75 & 80 & 65 \\
\hline Main HE 1 & $\begin{array}{c}\Delta \mathrm{T} \\
(\mathrm{K})\end{array}$ & 3.6 & 0.5 & 10 \\
\hline Main HE 2 & $\begin{array}{c}\Delta \mathrm{T} \\
(\mathrm{K})\end{array}$ & 4.8 & 0.5 & 10 \\
\hline Re-heaters & $\begin{array}{c}\Delta \mathrm{T} \\
(\mathrm{K})\end{array}$ & 3 & 1 & 15 \\
\hline Intercoolers & $\begin{array}{c}\Delta \mathrm{T} \\
(\mathrm{K})\end{array}$ & 3 & 1 & 15 \\
\hline Flasher & $\mathrm{p} \mathrm{(bar)}$ & 1.1 & 1.2 & 1.014 \\
\hline
\end{tabular}

\section{Results}

Figure 2 shows the results obtained from the advanced exergy analysis. The compressors are the components with the highest share of the exergy destruction within the system. The only component with a higher avoidable than unavoidable exergy destruction is the main heat exchanger in the discharge unit, more than $60 \%$ of the exergy destruction could be avoided if the component operates with a lower minimum temperature difference.

$60 \%$ of the exergy destruction within the compressors and $70 \%$ of the exergy destruction within the turbines is unavoidable $95 \%$ of the exergy destruction of the reheaters in the discharge unit is unavoidable, representing the components with the highest percentage of unavoidable exergy destruction.

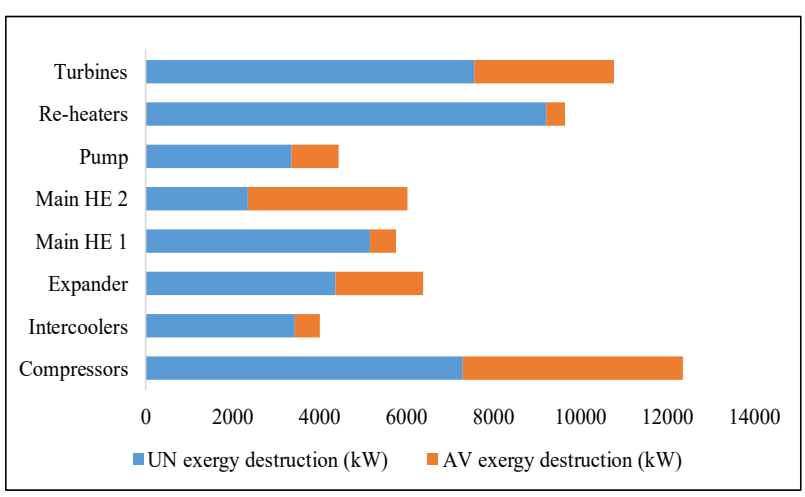

Fig. 2. Exergy destruction of every component divided by avoidable and unavoidable parts

Figure 3 represents the further split into endogenous and exogenous part for the exergy destruction. For all components, the avoidable exogenous exergy destruction is higher than the avoidable endogenous exergy destruction. In order to reduce the exergy destruction within a component the remaining components must be improved. For instance, to reduce the exergy destruction within the main heat exchanger in the discharge unit, the remaining components must be improved as well, since they are highly dependent from each other. 


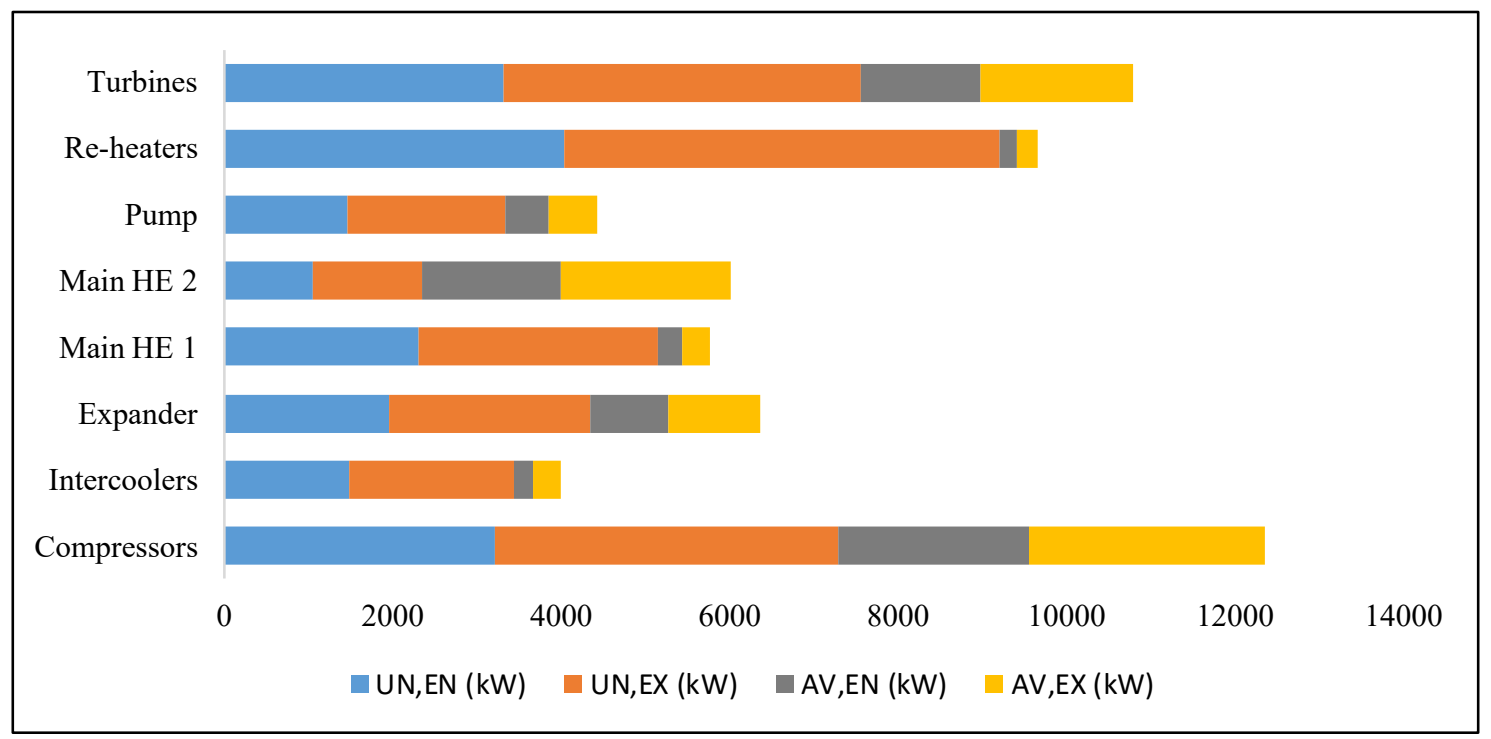

Fig. 1. Split of avoidable/unavoidable and endogenous/exogenous exergy destruction

Table 2 summarizes the values of the unavoidable and avoidable investment costs within the components with the highest avoidable investment cost in the LAES system under study. For the turbomachinery $80 \%$ of unavoidable exergy destruction was consider and for the heat exchangers equations cost (previously published and discussed in detail in [6]) were used to calculate the new investment cost in the conditions of worst performance [8]. The component with the highest possibility for improvement is the re-heater 6 , since $40 \%$ of its investment cost could be avoided if the heat exchanger operates with a minimum temperature approach of $15 \mathrm{~K}$ and not $3 \mathrm{~K}$.

Table 2. Splitting the investment cost into avoidable and unavoidable for the LAES system

\begin{tabular}{|c|c|c|c|c|}
\hline Component & $\begin{array}{c}\dot{Z}_{k, \boldsymbol{A}}{ }^{R} \\
(€ / \mathbf{h})\end{array}$ & $\begin{array}{c}\dot{Z}_{k, A}{ }^{U N} \\
(€ / h)\end{array}$ & $\begin{array}{c}\dot{Z}_{k, A}{ }^{A V} \\
(\boldsymbol{(} / \mathbf{h})\end{array}$ & $\begin{array}{c}\dot{Z}_{k, A}{ }^{A V} \\
(\mathbf{\%})\end{array}$ \\
\hline $\begin{array}{l}\text { Main heat } \\
\text { exchanger } 2\end{array}$ & 2621 & 1960 & 661 & 25 \\
\hline Turbine 1 & 975 & 780 & 195 & 20 \\
\hline Turbine 2 & 955 & 764 & 191 & 20 \\
\hline Turbine 3 & 949 & 759 & 190 & 20 \\
\hline Turbine 4 & 948 & 758 & 190 & 20 \\
\hline $\begin{array}{l}\text { Cryogenic } \\
\text { pump }\end{array}$ & 844 & 675 & 169 & 20 \\
\hline $\begin{array}{l}\text { Main heat } \\
\text { exchanger } 1\end{array}$ & 772 & 712 & 61 & 8 \\
\hline Re-heater 6 & 233 & 139 & 94 & 40 \\
\hline
\end{tabular}

The turbines represent the highest share of total cost of exergy destruction within the system for its elevated cost, as shown in Figure 4. By increasing the efficiency of the turbines $2 \%$-point (from $90 \%$ to $92 \%$ ), the cost associated with the exergy destruction for these components can be reduced by $30 \%$. The most relevant component is main heat exchanger 2 in the discharge unit, which has $60 \%$ of avoidable cost of exergy destruction. However, this component operates at cryogenic temperatures and a more efficient component would be significantly expensive. The intercoolers and reheaters operate at quasi optimal conditions, because almost all cost of exergy destruction is unavoidable.

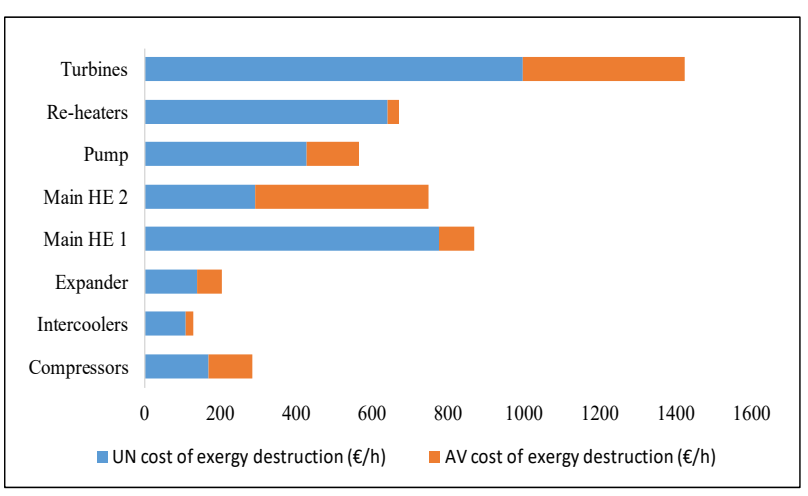

Fig. 2. Distribution of the avoidable and unavoidable cost of exergy destruction

The sum $\left(\dot{Z}_{k}+\dot{C}_{D, k}\right)$ and its distribution between avoidable and unavoidable parts is presented in Figure 5. The main heat exchangers and the turbines play an important role because of their high cost. 


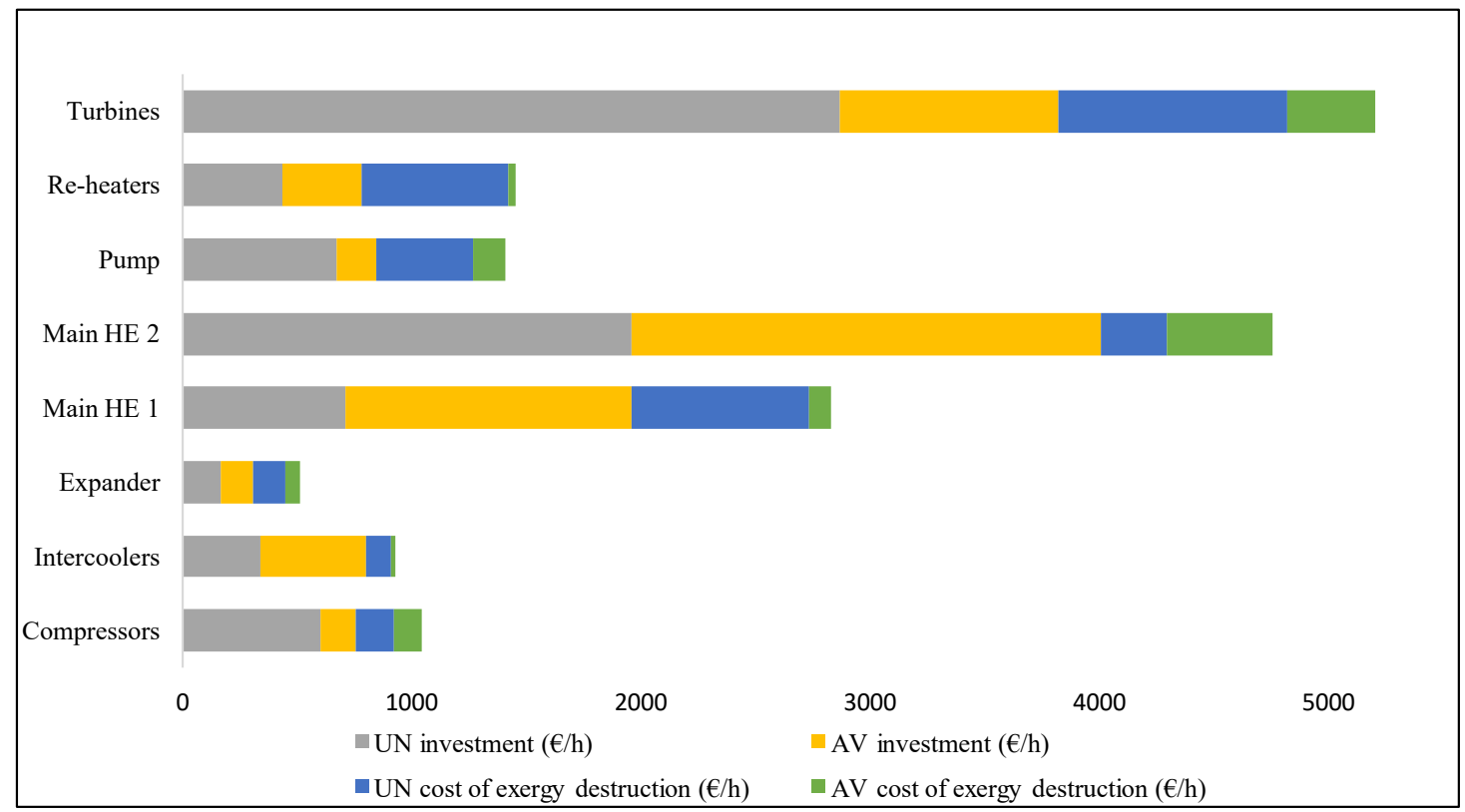

Fig. 3. Division of the sum of investment cost and cost of exergy destruction into avoidable and unavoidable parts $\left(\dot{Z}_{k},+\dot{C}_{D, k}\right)$

Within the exergoenvironmental analysis, the environmental impact due to the exergy destruction of each component was calculated. Operating at the best performance conditions, the system has an environmental impact of $66 \%$ (calculated using Eco-Indicator 99), that cannot be avoided. Nevertheless, some components such as the compressors have $43 \%$ of avoidable exergoenvironmental impact. The component that has the highest avoidable environmental impact is main heat exchanger in the discharge unit, it has $58 \%$ of avoidable exergoenvironmental impact. Figure 6 represents the distribution between avoidable and unavoidable exergoenvironmental impact due to the exergy destruction in each component. The turbomachinery has a high share in the total environmental impact of the LAES system, as well as the reheaters.

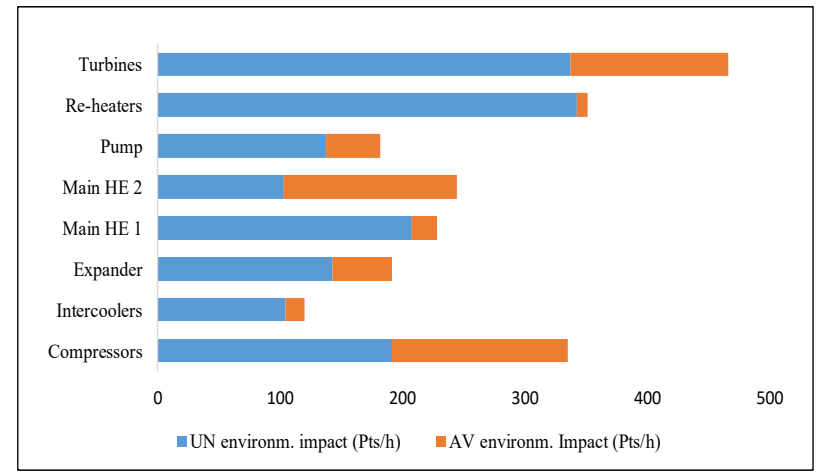

Fig. 4. Avoidable and unavoidable environmental impact associated with exergy destruction

\section{Conclusions}

1. $59-70 \%$ of the exergy destruction in the turbomachinery is unavoidable with exception of the cryogen pump (40\%).
2. The component with the highest possibility for improvement in performance and cost is the main heat exchanger 2 in the discharge unit.

3. The improvement of the isentropic efficiency in the turbomachinery avoids $30-41 \%$ of the cost of exergy destruction in the respective component.

4. The total LAES system could prevent $34 \%$ of its environmental impact due to avoidable exergy destruction. $M$ ain contributors are the turbines and compressors.

5. Exogenous exergy destruction is higher than endogenous for all components.

6. The exergy destruction of any of the components can be reduced by improving the remaining components.

\section{Nomenclature}

$b \quad$ specific environmental impact, $\mathrm{Pts} / \mathrm{kJ}$

$B$ environmental impact rate, $\mathrm{Pts} / \mathrm{h}$

C specific cost, $\$ / \mathrm{kW}$

C cost rate, $\$ / \mathrm{h}$

E exergy, $\mathrm{kWh}$

$p \quad$ pressure, bar

$T$ temperature, $\mathrm{K}$

CAES Compressed Air Energy Storage

CES Cryogenic-based Energy Storage

$H E$ heat exchanger

LAES Liquid Air Energy Storage

Pump cryogenic pump

PHS Pumped Hydro Storage

$\mathrm{Z} \quad$ investment cost 


\section{Greek symbols}

$\begin{array}{ll}\varepsilon & \text { exergetic efficiency, \% } \\ \eta & \text { isentropic efficiency, \% } \\ \Delta & \text { Difference }\end{array}$

\section{Subscripts and superscripts}

$\begin{array}{ll}\cdot & \text { time rate } \\ \mathrm{AV} & \text { avoidable } \\ \mathrm{D} & \text { destruction } \\ E N & \text { endogenous } \\ E X & \text { exogenous } \\ \mathrm{F} & \text { fuel } \\ \mathrm{H} & \text { hybrid } \\ k & \text { refers to a component } \\ \mathrm{L} & \text { losses } \\ \mathrm{P} & \text { product } \\ \mathrm{R} & \text { real } \\ \mathrm{T} & \text { theoretical } \\ \text { tot } & \text { total } \\ \mathrm{UN} & \text { unavoidable }\end{array}$

\section{Acknowledgement}

The authors acknowledge the financial support of the Bundesministerium für Bildung und Forschung/ Federal Ministry of Education, the Research (BMBF) under the Transnational Education project (ID 57128418) of the German Academic Exchange Service (DAAD) and Jimena Incer Valverde acknowledge the economical support of the University of Costa Rica during the preparation of this research.

\section{References}

1. IEA, International Energy Agency, 5 February 2019. [Online]. Available: https://www.iea.org/renewables2018/ (2018).

2. The Linde Group, Air separation plants. History and technological progress, Linde AG, Pullach, Germany, (2017).

3. Pérez, J., Sarasúa, J., Wilhelmi, J., Contribution of a hydraulic short-circuit pumped-storage power plant to the load-frequency regulation of an isolated power system, Science Direct ELSEVIER, pp. 199-211, (2014)

4. Howe, T., Pollman, A., Gannon, A., Operating Range for a Combined, Building-Scale Liquid Air Energy Storage and Expansion System: Energy and Exergy Analysis, entropy, (2018).

5. Hamdy, S., Morosuk, T., Tsatsaronis, G., Cryogenics-based energy storage: Evaluation of cold exergy recovery cycles, Energy, pp. 1069-1080, (2017).

6. Sciacovellia, A., Smitha, D., Navarroa, H., Lia, Y., Dinga, Y., Liquid air energy storage - Operation and performance of the first pilot plant in the world, ECOS 29Th International Conference on Efficiency, Cost and Optimization, (2016).
7. HighviewPowerStorage, Liquid Air Energy Storage, United Kingdom, (2017).

8. Hamdy, S., Morosuk, T., Tsatsaronis, G., Exergetic and economic assessment of integrated cryogenic energy storage systems, Cryogenics journal, (2019).

9. Bejan, A., Tsatsaronis, G., Moran, M., Thermal Design and Optimization, New York, United States: Wiley, (1996).

10. Lazzaretto, A., Tsatsaronis, G., A systematic and general methodology for calculating efficiencies and costs in thermal systems, Energy Int. J., pp. Vol. 31, pp.1257-1289., (2006).

11. Meyer, L., Tsatsaronis, G., Buchgeister, J., Schebek, L., Exergoenvironmental analysis for evaluation of the environmental impact of energy conversion systems, Energy Int. J., pp. Vol. 34, pp.75-89, (2009).

12. Tsatsaronis, G., Morosuk, T., Understanding and improving energy conversion systems with the aid of exergy-based methods, Int. J. Exergy, (2012).

13. Goedkoop, M., Spriensma, R., The eco-indicator 99: a damage oriented method for Life Cycle Impact assessment, Methodology Report, (2000).

14. S. P. a. t. E. Ministry of Housing, " Eco-indicator 99 Manual for Designers: A damage oriented method for Life cycle impact assessment," 6 March 2019. [Online]. Available: : https://www.presustainability.com/download/EI9

15. Kelly, S., Tsatsaronis, G., Morosuk, T., Advanced exergetic analysis: approaches for splitting the exergy destruction into endogenous and exogenous parts, Energy Int. J., pp. Vol. 34, pp.384-391., (2009).

16. Tsatsaronis, G., Moung-Ho, P., On avoidable and unavoidable exergy destructions and investment costs in thermal systems, Energy Conversion and Management, pp. 1259-1270, (2002). 